\title{
Chemiluminescence of $\mathrm{ClO}_{3}^{-}-\mathrm{SO}_{3}^{2-}-\mathrm{Rh} 6 \mathrm{G}-\mathrm{SDBS}$ System and Its Application to the Determination of Sulfite
}

\author{
CHENG, Xiang-Lei(程祥磊)ＺＺHAO, Li-Xia(赵利霞)ＬIN, Jin-Ming*(林金明) \\ State Key Laboratory of Environmental Chemistry and Ecotoxicology, Research Center for Eco-Environmental \\ Sciences, Chinese Academy of Sciences, Beijing 100085, China
}

\begin{abstract}
Based on the micelle synergism mechanism, a chemiluminescence (CL) flow system for the determination of sulfite was described. The CL signal generated from the reaction of chlorate with sulfite in acidic solution was very weak, while the interfusion of sodium dodecylbenzenesulfonate (SDBS) resulted in a highly chemiluminescent intensity. The major goal of this work was to investigate and develop the SDBS micelle synergetic CL system. The mechanism was proposed and proved by spectrometry. The results indicated that the unique structure of SDBS micelles promoted the aggregation of rhodamine $6 \mathrm{G}(\mathrm{Rh} 6 \mathrm{G})$ and a much easier energy transfer, leading to a marked shift to red in the CL emission. This CL system was developed for the determination of sulfite and the concentration of sulfite was proportional to the $\mathrm{CL}$ intensity in the range of $5.0 \times 10^{-8}-1.0 \times 10^{-5} \mathrm{~mol} / \mathrm{L}$ with the detection limit of $1.7 \times 10^{-8}$ $\mathrm{mol} / \mathrm{L}(\mathrm{S} / \mathrm{N}=3)$. The relative standard deviation was $3.3 \%$ for $1.0 \times 10^{-6} \mathrm{~mol} / \mathrm{L}$ sulfite solution with eleven repeated measurements. This method was successfully applied to the determination of sulfite in powder sugar.
\end{abstract}

Keywords chemiluminescence, sulfite, micelle synergism

\section{Introduction}

The utilization of organized surfactant assemblies as a chemiluminescence $(\mathrm{CL})$ reaction medium is currently of interest for improving analytical CL characteristics, which was reviewed by Lin and Yamada. ${ }^{1}$ There are several potentially significant advantages in using micellar systems as the medium for analytical CL measurements, and of all these advantages, the use of aqueous micellar solutions to enhance the CL intensity from CL reaction systems was the most popular. ${ }^{2-5}$ The first analytical application of a CL reaction to a micellar medium was reported by Yamada and Suzuki. ${ }^{4}$ The mechanism of energy transfer of superoxide anionic radicals and 1,10-phenanthroline was developed. To our best knowledge, none of the authors mentioned the emission shift in the CL spectrum of the acceptor because of the addition of surfactants.

Flow injection analysis (FIA) coupled with CL (FIA-CL) has grown up rapidly, to bring together the advantages of these two techniques in simple and rapid instrumentation and improvement of sensitivity, selectivity and precision. The $\mathrm{CL}$ was produced by sulfite as follows: sulfite could be oxidized by copper(II) ${ }^{6}$ in an alkaline solution, and reacted with the chemiluminescent reagent luminol. ${ }^{7}$ In an acidic solution it could be oxidized by potassium permanganate, ${ }^{8}$ cerium(IV $)^{9}$ or potassium bromide. ${ }^{10}$ However, these methods suffered from high background and expensive reagents. Esteves da Silva et al. ${ }^{11}$ studied a chemiluminescent flow system for bromate detection based on the reaction of bromate and sulfite in acidic medium. Unfortunately, the system suffered from the interference of chloride or bromide ion. Huang and coworkers ${ }^{12,13}$ described a CL system for sulfite based on auto-oxidation sensitized by Rhodamine $6 \mathrm{G}(\mathrm{Rh} 6 \mathrm{G})$ in the presence of Tween 80, but only discussed the effect of surfactants by just citing the simple and general viewpoints. Additionally, the content of the dissolved oxygen in solutions was unstable and the whole system was sensitive to the change of the outer factors.

In this study, we found that sodium dodecylbenzenesulfonate (SDBS) could greatly improve the CL signal of chlorate-sulfite reaction. Moreover, it could overcome some disadvantages mentioned above to certain extent using $\mathrm{ClO}_{3}^{-}-\mathrm{SO}_{3}^{2-}-\mathrm{Rh} 6 \mathrm{G}-\mathrm{SDBS} \mathrm{CL}$ system for the detection of sulfite. Based on these, a highly sensitive method for the determination of sulfite was developed. In addition, the micelle synergism mechanism of surfactants on the CL emitted from chlorate-sulfite CL reaction was also studied in detail and the reasons of the red shift in the emission spectrum of $\mathrm{Rh} 6 \mathrm{G}$ were investigated.

\section{Experimental}

\section{Apparatus}

A BPCL ultraweak chemiluminescence analyzer

\footnotetext{
* E-mail: jmlin@mail.rcees.ac.cn; Tel. and Fax: 0086-10-62841953

Received April 21, 2005; revised August 9, 2005; accepted September 12, 2005.

Project supported by the National Fund for Distinguished Young Scholars of China (No. 20125514), the National Natural Science Foundation of China (Nos. 20437020, 50273046) and the Major Research Program of Chinese Academy of Sciences (No. KZCX3-SW-432).
} 
(Institute of Biophysics, Chinese Academy of Sciences, Beijing, China) was used to obtain batch CL signals. A schematic diagram of the FIA-CL system in this work was shown in Figure 1. Reagent solutions R1, R2 and $\mathrm{R} 3$ were delivered by peristaltic pumps $\mathrm{P}$ through three flow-lines: R1 was a carrier solution (Rh6G), R2 a mixture of $\mathrm{ClO}_{3}^{-}$in $\mathrm{HCOOH}$ and $\mathrm{R} 3$ a SDBS solution. The solution of sulfite or sample was injected by means of a $100 \mu \mathrm{L}$ loop valve injector placed close to a luminometer (lumiflow LF-800, Microtec NITI-ON, Funabashi, Japan). The fluorescence and absorption spectra were measured with an F-2500 fluorescence spectrometer (Hitachi, Tokyo, Japan) and a Shimadzu UV-2401 UV-visible recording spectrophotometer (Shimadzu, Kyoto, Japan), respectively. The spectrofluorimeter was also adopted for the measurement of CL spectra.

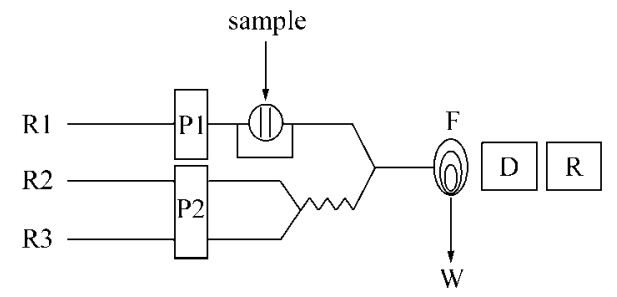

Figure 1 Schematic diagram of the FIA-CL flow system for the determination of sulfite. R1: $4.8 \mathrm{~mL} / \mathrm{min}$ of $0.5 \mathrm{mmol} / \mathrm{L} \mathrm{Rh} 6 \mathrm{G}$, $\mathrm{R} 2: 1.8 \mathrm{~mL} / \mathrm{min}$ of $1.0 \mathrm{~mol} / \mathrm{L} \mathrm{ClO}_{3}^{-}$in $5 \mathrm{mmol} / \mathrm{L} \mathrm{HCOOH}, \mathrm{R} 3$ : $1.8 \mathrm{~mL} / \mathrm{min}$ of $3 \%$ SDBS, D: detector, F: flow cell, P1 and P2: peristaltic pump, R: recorder, W: waste.

\section{Reagents}

Chemicals of analytical grade were used as received. Ultrapure water was obtained from a compact ultrapure water system $(18.3 \mathrm{M} \Omega \bullet \mathrm{cm}$, Barnstead, Iowa, USA). SDBS was purchased from Fisher Scientific (Hong Kong) Ltd. Standard solution of SDBS was prepared by further dilution of its stock solution $(6 \%, w)$. Rh6G was from Sigma-Aldrich Co., USA. A stock solution of $1.0 \times$ $10^{-2} \mathrm{~mol} / \mathrm{L}$ sulfite was prepared daily by dissolving $0.1260 \mathrm{~g}$ of anhydrous sodium sulfite (Beijing Yili Fine Chemical Ltd, Beijing, China) in $100.0 \mathrm{~mL}$ of water. A chlorate solution was obtained by dissolving sodium chlorate (Beijing Fangshan Yihua Chemical Plant, Beijing, China) in water. Formic acid was from Beijing Reagent Company (Beijing, China).

\section{Procedure}

For the CL spectrum, a continuous flow manifold incorporating an integrated Y-piece and a $90 \mu \mathrm{L}$ flow cell unit (Hitachi, Tokyo, Japan) was placed in front of the emission window of the spectrofluorimeter. A peristaltic pump with silicone tubing was used to continuously deliver reagent and analyte solution through 0.8 $\mathrm{mm}$ i.d. polytetrafluoroethene (PTFE) tubing to the flow cell where the CL reaction occurred. The excitation lamp was off and the emission slit width was opened maximally to $20 \mathrm{~nm}$ during the CL spectrum recording.

SDBS and acidic chlorate solutions were mixed via a
Y-shaped element. $100 \mu \mathrm{L}$ of sample or standard solution were injected into the carrier stream through a sixway valve. The output was fed to a computer equipped with the LUM-2000 data processing program of this Research Center.

A sample solution of sugar was prepared by dissolving $5.000 \mathrm{~g}$ of sugar in water and diluting with water to $100 \mathrm{~mL}$. $2.0 \mathrm{~mL}$ of the sample solution were transferred into a volumetric flask and diluted to $10 \mathrm{~mL}$. The final solution should contain $1.0 \times 10^{-6}-1.0 \times 10^{-5} \mathrm{~mol} / \mathrm{L}$ of sulfite and was processed as with pure aqueous sulfite solutions.

\section{Results and discussion}

\section{Kinetic characteristics of the CL reaction}

The CL profiles by the batch method for the mixtures of $\mathrm{ClO}_{3}^{-}, \mathrm{H}^{+}$, SDBS and $\mathrm{Rh} 6 \mathrm{G}$ solution are shown in Figure 2. The results indicated that mixing of $\mathrm{ClO}_{3}^{-}$in acidic solution with $\mathrm{SO}_{3}^{2-}$ solution generated weak CL emission (Figure 2a). When the SDBS solution was added, a stronger and sharper CL signal appeared (Figure 2b). Furthermore, a much stronger CL signal generated from the addition of the SDBS and Rh6G to a solution of $\mathrm{SO}_{3}^{2-}$ and an acidic sodium chlorate (Figure 2c). The maximum emission intensity was attained within $0.5 \mathrm{~s}$ and the CL reaction could be completed within $3.5 \mathrm{~s}$ after the reaction started. These results indicate that SDBS and Rh6G could sensitize the chlorate CL system and the reaction of SDBS with the reactive species is a fast CL process.

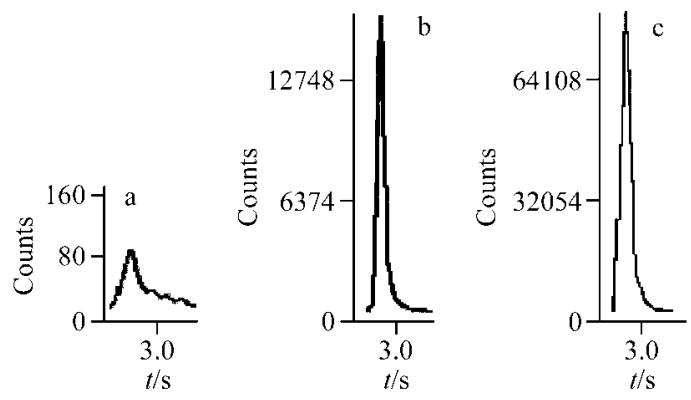

Figure $2 \mathrm{CL}$ profiles in the batch system. a: sulfite + chlorate in acidic solution; $b$ : SDBS $+a$; $c$ : Rh6G $+b$. The concentrations of $\mathrm{ClO}_{3}^{-}, \mathrm{SO}_{3}^{2-}, \mathrm{H}^{+}, \mathrm{SDBS}$ and Rh6G are $1.0 \times 10^{3}, 1.0,1.0 \times 10^{3}$, 2.5 and $0.1 \mathrm{mmol} / \mathrm{L}$.

\section{Effect of surfactant on the CL signal}

The effect of surfactants on the CL signals was significant, and almost no CL signals would be observed if there were no surfactants, which could be seen from the results of batch CL method. Various surfactants, including cationic, anionic and nonionic ones, were added to the reaction system. As can be seen from Table 1, the CL signals depended on the carbon number in the alkyl group of the surfactant reagents. Along with a decrease in carbon number of alkyl group, the CL intensity was decreased. Meanwhile, the CL intensity of such C16 
surfactants as CTAH, CTAC and CTAB were approximately at the same level. The reason was that the formation of micelles could prevent the CL signals from quenching by impurity. Due to the existence of $\mathrm{Rh}_{6 \mathrm{G}}{ }^{+}$ and electrostatic repulsion effect, energy transfer from $\mathrm{SO}_{2}^{*}$ to $\mathrm{Rh} 6 \mathrm{G}$ may not be so easy as cationic surfactants. However, the Rh6G molecules could associate to some extent with cationic micelles, most likely as a pseudo-monomer of the micelle, ${ }^{14}$ despite its positive charges. Hence the addition of Rh6G still enhanced the CL signals in the presence of cationic surfactants. With the existence of phenyl, SDBS was likely to form micelles with a unique structure that exhibits higher organization, stability and rigidity than those of normal micelle. On the other hand, the benzenesulfonate group of the SDBS has fluorescent characteristics, and it could act as a sensitizer in the CL reaction. ${ }^{15}$ Moreover, with the electrostatic attraction, the CL signals were further improved. Therefore, the enhancing effect of SDBS was the highest among all the surfactants experimented. For nonionic surfactants, the protection effect and electrostatic effect were intermediate, thus the relative CL intensity was moderate. In conclusion, the $\mathrm{CL}$ signals consisted in two steps: firstly, the protection process of $\mathrm{SO}_{2}^{*}$ which was the basis of CL, and secondly, the efficient energy transfer from $\mathrm{SO}_{2}^{*}$ to Rh6G. Without the progress of the first step, no further increase of CL would occur.

Table 1 Effect of some organized solutions on CL emission of flow-injection method

\begin{tabular}{lc}
\hline \multicolumn{1}{c}{ Surfactant } & $\begin{array}{c}\text { Relative CL } \\
\text { intensity }\end{array}$ \\
\hline None & 1 \\
Cetylethyl dimethylammonium bromide (CEDAB) & 25 \\
Cetyltrimethylammonium chloride (CTAC) & 26 \\
Cetyltrimethylammonium bromide (CTAB) & 21 \\
Cetyltrimethylammonium hydroxide (CTAH) & 30 \\
Myristyltrimethylammonium bromide (MTAB) & 15 \\
Dodecyltrimethylammonium bromid (DTAB) & 10 \\
Sodium dodecylbenzenesulfonate (SDBS) & 120 \\
Sodium dodecylsulfate (SDS) & 5 \\
Tween 20 & 22 \\
Tween 85 & 52 \\
Triton 100 & 22 \\
\hline
\end{tabular}

The effect of SDBS concentration on the relative CL intensity was studied at different concentrations from $0.02 \%-5 \%$. As illustrated in Figure 3, maximum CL intensity was obtained at a concentration of 3\% SDBS, namely under or above $3 \%$, a decrease of the CL intensity was caused. Therefore, $3 \%$ of SDBS was selected for this work.

\section{Effect of formic acid on the CL signal}

The redox reaction of chlorate and sulfite can occur only in the acid medium, and thus the preliminary study of six acids was carried out: formic acid, acetic acid, hydrochloric acid, nitric acid, phosphoric acid and sulfuric acid. The results showed that in formic acid the maximum CL signal was attained. The influence of different concentration of formic acid from 4 to $10 \mathrm{~m} \mathrm{~mol} /$ L was studied through the same flow manifold. A concentration of $5 \mathrm{mmol} / \mathrm{L}$ produced the maximum emission. Too low concentration of $\mathrm{HCOOH}$ could not reach enough $\mathrm{pH}$ value that the reaction needed while too high concentration would destroy the aggregation of Rh6G on the surface of SDBS micelles. Thus, $5 \times 10^{-3} \mathrm{~mol} / \mathrm{L}$ formic acid was selected for this work.

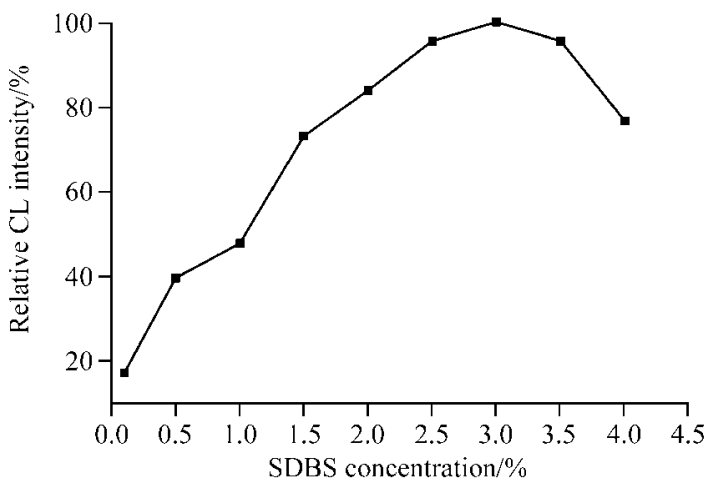

Figure 3 Effect of SDBS concentration on the sulfite CL emission. $\mathrm{HCOOH}: 5 \mathrm{mmol} / \mathrm{L}, \mathrm{ClO}_{3}^{-}: 1.0 \times 10^{3} \mathrm{mmol} / \mathrm{L}$, Rh6G: 0.1 $\mathrm{mmol} / \mathrm{L}$.

\section{Effect of the concentration of oxidant on the CL sig- nal}

The concentration of $\mathrm{ClO}_{3}^{-}$was varied between 1 and $1.5 \times 10^{3} \mathrm{mmol} / \mathrm{L}$. As shown in Figure 4, CL intensity of sulfite increased with the concentration of chlorate up to $1.0 \times 10^{3} \mathrm{mmol} / \mathrm{L}$, and thereafter decreased with the increase of concentration. Lower concentration did not react adequately with sulfite, while too high concentration would result in separating out of sodium chlorate solid in the microheterogeneous solution and the waste of reagent. Therefore, $1.0 \times 10^{3} \mathrm{mmol} / \mathrm{L}$ of chlorate was selected for present study.

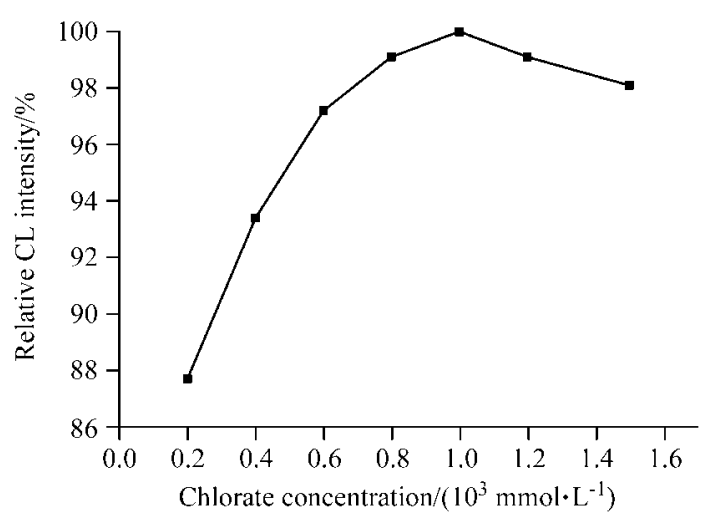

Figure 4 Effect of chlorate concentration on the sulfite CL emission. HCOOH: 5 mmol/L, SDBS: $1 \%$, Rh6G: 0.1 mmol/L. 


\section{Effect of Rh6G on the CL signal}

In an attempt to further improve the sensitivity of the CL signal, a few of enhancers such as acridine, calcein, erythrosine B, dichlorofluorescein, fluoroscein, 9-phenyl2,3,7-trihydroxy-6-fluorone (PTHF), Rh6G, Rhodamine $\mathrm{B}(\mathrm{RhB})$ and uranine were included in the carrier stream. The results showed that RhB and Rh6G at the same concentration could provide the largest signal. Because of the strong absorption of $\mathrm{RhB}$ on the flow tube wall, Rh6G was finally selected.

The effect of Rh6G was also studied by testing solutions with concentrations rising from $1.0 \times 10^{-3}$ to 1.0 $\mathrm{mmol} / \mathrm{L}$. A concentration of $5.0 \mathrm{mmol} / \mathrm{L}$ was selected for further work. A concentration lower than 5.0 $\mathrm{mmol} / \mathrm{L}$ resulted in decrease of efficiency of energy transfer, while a concentration higher than that led to strong self-absorption and high background noise.

\section{Effect of flow rate on the CL signal}

In order to determine the optimum operating conditions of the flow system, the signal for $1.0 \times 10^{-5} \mathrm{~mol} / \mathrm{L}$ sulfite was measured with respect to the flow rate of the reagent solutions and sample solution. The flow rate of the carrier Rh6G (R1) was different from those of both chlorate (R2) and surfactant (R3). Hence, flow rates from 1.0 to $7.5 \mathrm{~mL} / \mathrm{min}$ were tested. The results showed that the signal intensity increased with the increase of flow rate of R1. However, too high flow rate led to much consumption of regent and sample solutions but little gain of CL intensity and unstable decrease of CL signal. It was recommended to supply $\mathrm{R} 2$ and $\mathrm{R} 1$ at 1.8 and $4.8 \mathrm{~mL} / \mathrm{min}$, respectively.

Effect of SDBS synergetic mechanism on the CL signal

In order to investigate the possible mechanism of this CL reaction, the CL emission spectrum of sulfite after mixing with $\mathrm{ClO}_{3}^{-}$in acid solution and SDBS was recorded. The results showed one emission profile extending from 400 to $550 \mathrm{~nm}$ with maximum emission intensity around $460 \mathrm{~nm}$ (Figure 5a), corresponding to the $\mathrm{CL}$ emission of $\mathrm{SO}_{2}^{*}$ measured by Stauff and Jaeschke ${ }^{16}$ through interference filters. But, surprisingly, the CL emission recorded, when sulfite and Rh6G were reacted with chlorate-SDBS, was at $575 \mathrm{~nm}$ (Figure 5b), which did not coincide with the fluorescence emission spectrum of Rh6G $(552 \mathrm{~nm})$.

To clarify the reasons of this discordance, the absorption, CL and fluorescence spectra were recorded. Firstly, the absorption spectra of the solutions, shown in Figure 6, had no difference between those before and after CL reaction, indicating that no new substance was produced. Secondly, the CL spectra of different concentration of Rh6G, $1.0 \times 10^{-2}, 5.0 \times 10^{-2}$ and $0.1 \mathrm{mmol} / \mathrm{L}$, were recorded as shown in Figure 7. An obvious phenomenon was observed that the emission wavelength shifted from 560 to $575 \mathrm{~nm}$, to suggest that the concentration of Rh6G should be involve with the red shift.

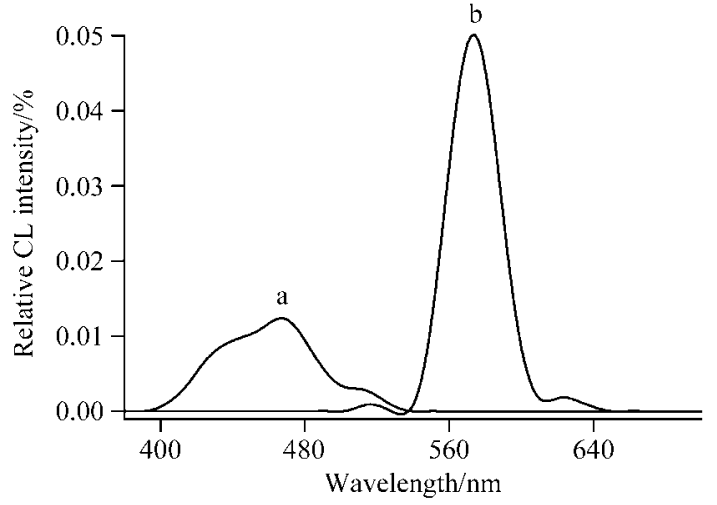

Figure $5 \mathrm{CL}$ spectra of $\mathrm{NaClO}_{3}-\mathrm{Na}_{2} \mathrm{SO}_{3}-\mathrm{SDBS},\left[\mathrm{Na}_{2} \mathrm{SO}_{3}\right]=1.0$ $\mathrm{mmol} / \mathrm{L}$ (a), and $\mathrm{NaClO}_{3}-\mathrm{Na}_{2} \mathrm{SO}_{3}$-SDBS-Rh6G, $\left[\mathrm{Na}_{2} \mathrm{SO}_{3}\right]=0.1$ $\mathrm{mmol} / \mathrm{L}$ (b) with $\left[\mathrm{NaClO}_{3}\right]=1.0 \times 10^{3} \mathrm{mmol} / \mathrm{L},[\mathrm{HCOOH}]=5$ $\mathrm{mmol} / \mathrm{L},[\mathrm{SDBS}]=3 \%$ and $[\mathrm{Rh} 6 \mathrm{G}]=0.5 \mathrm{mmol} / \mathrm{L}$.

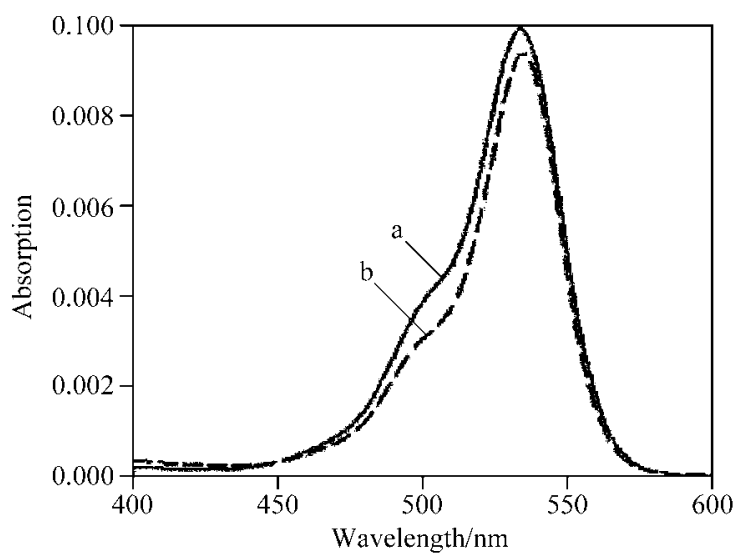

Figure 6 Absorption spectra of $\mathrm{NaClO}_{3}-\mathrm{SDBS}-\mathrm{Rh} 6 \mathrm{G}$ (a) and $\mathrm{NaClO}_{3}-\mathrm{Na}_{2} \mathrm{SO}_{3}-\mathrm{SDBS}-\mathrm{Rh} 6 \mathrm{G}$ (b) at $\left[\mathrm{NaClO}_{3}\right]=1.0 \times 10^{3} \mathrm{mmol} /$ $\mathrm{L},[\mathrm{HCOOH}]=5 \mathrm{mmol} / \mathrm{L},\left[\mathrm{Na}_{2} \mathrm{SO}_{3}\right]=1.0 \mathrm{mmol} / \mathrm{L},[\mathrm{SDBS}]=3 \%$ and $[\mathrm{Rh} 6 \mathrm{G}]=1.0 \times 10^{-2} \mathrm{mmol} / \mathrm{L}$.

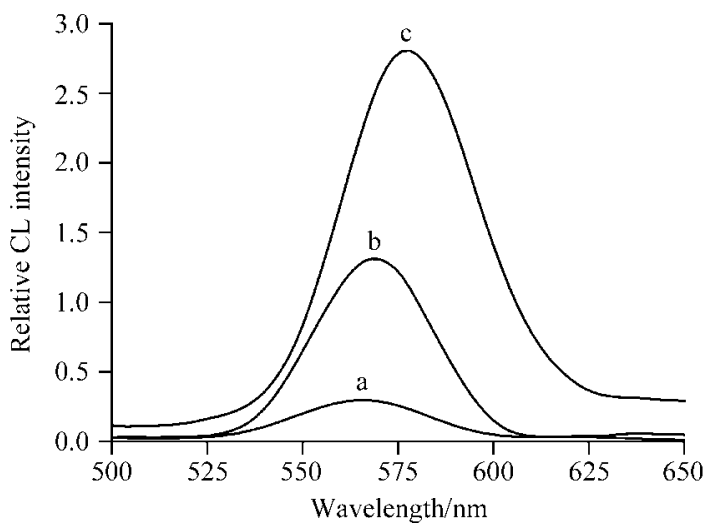

Figure $7 \mathrm{CL}$ spectra of $\mathrm{NaClO}_{3}-\mathrm{Na}_{2} \mathrm{SO}_{3}-\mathrm{SDBS}-\mathrm{Rh} 6 \mathrm{G}$ with $[\mathrm{Rh} 6 \mathrm{G}]=1.0 \times 10^{-2} \mathrm{mmol} / \mathrm{L}(\mathrm{a}),[\mathrm{Rh} 6 \mathrm{G}]=5.0 \times 10^{-2} \mathrm{mmol} / \mathrm{L}$ (b), $[\mathrm{Rh} 6 \mathrm{G}]=0.1 \mathrm{mmol} / \mathrm{L}$ (c) at $\left[\mathrm{NaClO}_{3}\right]=1.0 \times 10^{3} \mathrm{mmol} / \mathrm{L}$, $[\mathrm{HCOOH}]=5 \mathrm{mmol} / \mathrm{L},\left[\mathrm{Na}_{2} \mathrm{SO}_{3}\right]=1.0 \mathrm{mmol} / \mathrm{L}$ and $[\mathrm{SDBS}]=$ $3 \%$. 
However, none of the fluorescence spectra under various media of water, acid and acidic chlorate had the phenomenon of red shift. The results implied that the red shift of spectrum of Rh6G should be also related to the addition of SDBS. Finally, the fluorescent spectra of different concentration of Rh6G, $1.0 \times 10^{-2}, 5.0 \times 10^{-2}$ and $0.1 \mathrm{mmol} / \mathrm{L}$, in the absence and presence of SDBS were investigated, as shown in Figure 8. To our satisfaction, the emission spectra of Rh6G shifted from 559 $\mathrm{nm}$ to $570 \mathrm{~nm}$ in the presence of SDBS, while those without SDBS almost had no shift.
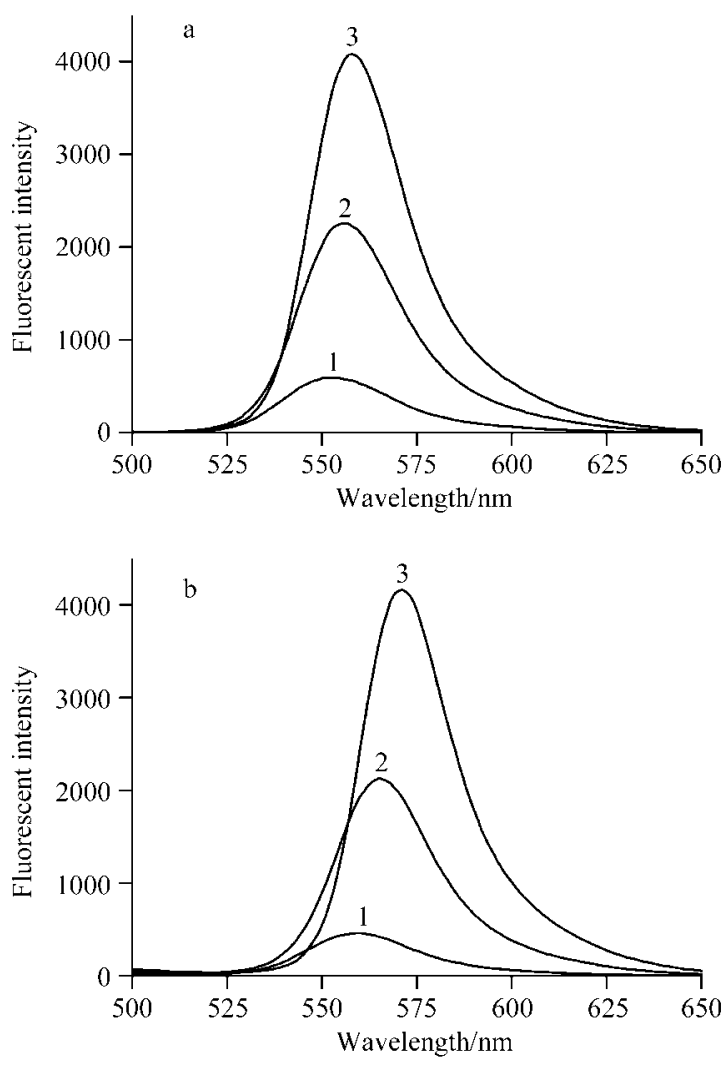

Figure 8 Fluorescence spectra of Rh6G without (a) and with SDBS (b). (a) Line 1, $[\mathrm{Rh} 6 \mathrm{G}]=1.0 \times 10^{-2} \mathrm{mmol} / \mathrm{L}$; line 2, $[\mathrm{Rh} 6 \mathrm{G}]=5.0 \times 10^{-2} \mathrm{mmol} / \mathrm{L}$; line $3,[\mathrm{Rh} 6 \mathrm{G}]=0.1 \mathrm{mmol} / \mathrm{L} ; .(\mathrm{b})$ line $1,[\mathrm{Rh} 6 \mathrm{G}]=1.0 \times 10^{-2} \mathrm{mmol} / \mathrm{L}$; line $2,[\mathrm{Rh} 6 \mathrm{G}]=5.0 \times 10^{-2}$ $\mathrm{mmol} / \mathrm{L}$; line $3,[\mathrm{Rh} 6 \mathrm{G}]=0.1 \mathrm{mmol} / \mathrm{L}$ at $\left[\mathrm{NaClO}_{3}\right]=1.0 \times 10^{3}$ $\mathrm{mmol} / \mathrm{L},[\mathrm{HCOOH}]=5 \mathrm{mmol} / \mathrm{L}$ and $[\mathrm{SDBS}]=3 \%$.

Based on these, the synergetic mechanism could be expressed as follows: $\mathrm{pH}$ value of this $\mathrm{CL}$ system was approximately $3-4$, while $\mathrm{p} k_{\mathrm{a} 1}$ and $\mathrm{p} k_{\mathrm{a} 2}$ of $\mathrm{H}_{2} \mathrm{SO}_{3}$ were 1.90 and 7.20, respectively, thus most of $\mathrm{SO}_{3}^{2-}$ existed in the form of $\mathrm{HSO}_{3}^{-}$. Moreover, the oxidation potential of chlorate $(1.45 \mathrm{~V})$ was higher than that of $\mathrm{SO}_{4}^{2-}$ $\left(E_{\mathrm{SO}_{4}^{2-} / \mathrm{SO}_{3}^{2-}}=0.17 \mathrm{~V}\right)$, and consequently chlorate could oxidize $\mathrm{HSO}_{3}^{-}$into $\mathrm{SO}_{4}^{2-}$. The CL emission observed in the $\mathrm{HSO}_{3}^{-} / \mathrm{H}^{+} / \mathrm{SO}_{3}^{2-}$ system may be due to the formation of $\mathrm{SO}_{2}{ }^{*}$, which took place as the reactions followed: ${ }^{5,13,17}$

$$
\mathrm{ClO}_{3}^{-}+6 \mathrm{HSO}_{3}^{-}+6 \mathrm{H}^{+} \longrightarrow 6 \mathrm{HSO}_{3} \bullet+\mathrm{Cl}^{-}+3 \mathrm{H}_{2} \mathrm{O}
$$

$$
\begin{aligned}
& 2 \mathrm{HSO}_{3} \bullet \longrightarrow \mathrm{S}_{2} \mathrm{O}_{6}^{2-}+2 \mathrm{H}^{+} \\
& \mathrm{S}_{2} \mathrm{O}_{6}^{2-} \longrightarrow \mathrm{SO}_{4}^{2-}+\mathrm{SO}_{2}^{*}
\end{aligned}
$$

When SDBS was added, the SDBS micelles were formed. As can be seen in Figure 9, the cage structure of the micelle is helpful for stabilizing the excited state to prevent it from quenching. ${ }^{13,18}$ Meanwhile, the compartmentalization due to the formation of micelles could prevent the unstable excited state of $\mathrm{SO}_{2}^{*}$ generated in this CL reaction from quenching, ${ }^{15}$ making CL intensity of the present system increased from 79 to 15936 counts.

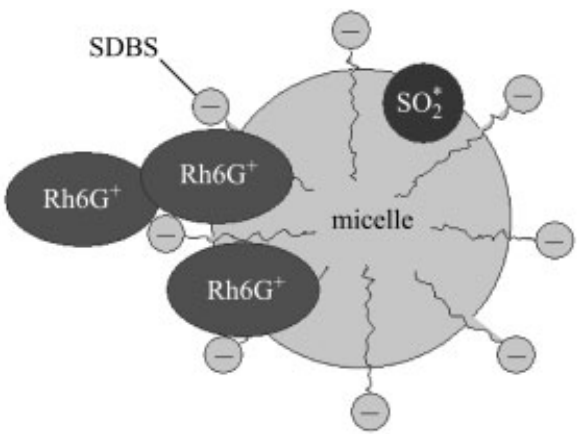

Figure $9 \mathrm{CL}$ mechanism of excited sulfur dioxide $\mathrm{SO}_{2}^{*}-\mathrm{Rh} 6 \mathrm{G}$ system in micelle medium.

With the addition of Rh6G, as a result of existence in the form of cations in the aqueous solution, the sensitized Rh6G should be more easily aggregated around the micelle of anionic surfactant SDBS. The emitter species $\mathrm{SO}_{2}^{*}$ was easier to be dissolved in hydrophobic medium than in water, ${ }^{5}$ resulting in an occurrence of more efficient energy transfer from $\mathrm{SO}_{2}^{*}$ to $\mathrm{Rh} 6 \mathrm{G}$, since the transfer of electron excitation energy in solution could be realized up to a distance of $10 \mathrm{~nm}$ (Perrin-Forster mechanism). When the concentration of Rh6G was low enough $\left(\leqslant 1.0 \times 10^{-2} \mathrm{mmol} / \mathrm{L}\right)$, the reaction below occurred:

$$
\begin{aligned}
& \mathrm{SO}_{2}^{*}+\mathrm{Rh} 6 \mathrm{G} \longrightarrow \mathrm{SO}_{2}+\mathrm{Rh}^{*} \mathrm{G}^{*} \\
& \mathrm{Rh}^{*} \mathrm{G}^{*} \longrightarrow \mathrm{Rh} 6 \mathrm{G}+h v(\lambda \approx 560 \mathrm{~nm})
\end{aligned}
$$

Because of electrostatic effect between anionic surfactant SDBS and Rh6G molecules, Rh6G molecules could be aggregated on the surface of micelles with a concentration higher than bulk solution. Then, in the hydrophobic-lipophilic interaction, ${ }^{19}$ when the concentration of Rh6G was higher enough $\left(\geqslant 5.0 \times 10^{-2}\right.$ $\mathrm{mmol} / \mathrm{L})$, polymeric Rh6G (Rh6G) molecules were formed. These polymers were excited more easily compared to monomer of Rh6G, which led to higher efficiency of energy transfer and red shift of CL emission spectrum.

$$
\mathrm{SO}_{2}^{*}+(\mathrm{Rh} 6 \mathrm{G})_{n} \longrightarrow \mathrm{SO}_{2}+(\mathrm{Rh} 6 \mathrm{G})_{n}^{*}
$$


$(\mathrm{Rh} 6 \mathrm{G})_{n}^{*} \longrightarrow n \mathrm{Rh} 6 \mathrm{G}+h v(\lambda \approx 575 \mathrm{~nm})$

\section{Analytical characteristics}

A calibration graph obtained by the use of the optimized system was linear with increasing concentration of sulfite over the range of $5.0 \times 10^{-8}-1.0 \times 10^{-5}$ $\mathrm{mol} / \mathrm{L}$. The maximum peak height increased linearly with increase in sulfite concentration, as expressed by the equations $I=-4.5+1.1 \times 10^{8} c, r=0.9996$ during $c=5.0 \times 10^{-8}-5.0 \times 10^{-7} \mathrm{~mol} / \mathrm{L}$ and $I=-88.5+3.3 \times$ $10^{8} c, r=0.9986$ during $c=5.0 \times 10^{-7}-1.0 \times 10^{-5} \mathrm{~mol} / \mathrm{L}$. The detection limit was $1.7 \times 10^{-8} \mathrm{~mol} / \mathrm{L}(S / \mathrm{N}=3)$, and the relative standard deviation was $3.3 \%$ for $1.0 \times 10^{-6}$ $\mathrm{mol} / \mathrm{L}$ sulfite solution with eleven repeated measurements. As compared in Table 2, the present method for the determination of sulfite has a wide linear range and low detection limit.

\section{Interferences}

The tolerable concentration ratios with respect to $1.0 \times 10^{-6} \mathrm{~mol} / \mathrm{L}$ sulfite for interference at $5 \%$ level were examined. 1000-fold of $\mathrm{Cl}^{-}, \mathrm{K}^{+}, \mathrm{NO}_{3}^{-}, \mathrm{Mg}^{2+}$, $\mathrm{SO}_{4}^{2-}, \mathrm{Ca}^{2+}$, ascorbic acid, $D$ - or $L$-phenylalanine, 500 -fold of glucose, $\mathrm{S}^{2-}, \mathrm{HPO}_{4}^{2-}, \mathrm{PO}_{4}^{3-}, 100$-fold of $\mathrm{Co}^{2+}$, citrate, citric acid, 50-fold of $\mathrm{NH}_{4}^{+}$, methanol, ethanol, $L$-tyrosine, tartaric acid, malic acid, oxalic acid, lactic acid, 10-fold of $\mathrm{Br}^{-}, \mathrm{Mn}^{2+}, \mathrm{Cu}^{2+}$, and 5-fold of $\mathrm{Fe}(\mathrm{III}), \mathrm{Fe}(\mathrm{II})$ had almost no effect on the determination of high concentration level of sulfite.

\section{Sample analysis}

Powder sugar is one of the most widely used materials in various foods and the sources of the contamination of the sulfite in foods. Thus, the determination of sulfite in powder sugar is of importance. Now, the proposed method was applied to the determination of sulfite in powder sugar. The recoveries were good enough for practical use and all determination values are listed in Table 3. The sulfite content in sugar was 28.1 and $17.2 \mathrm{mg} / \mathrm{kg}$, respectively.

\section{Conclusion}

It could be concluded that the sensitizing effect and the red shift of CL emission spectrum of Rh6G were due to the micelle synergism. A possible synergetic mechanism was proposed based on the study of fluorescence, absorption and CL emission spectra. A rapid and economic FIA-CL technique for the determination of sulfite was established, with good linearity, accuracy, precision and detection limit.

Table 2 Comparison of the present CL method for the determination of sulfite with other reported methods

\begin{tabular}{|c|c|c|c|}
\hline Method & Detection limit $/\left(\mathrm{mmol} \cdot \mathrm{L}^{-1}\right)$ & Dynamic linear range $/\left(\mathrm{mmol} \cdot \mathrm{L}^{-1}\right)$ & Ref. \\
\hline Proposed CL & $1.7 \times 10^{-5}$ & $5.0 \times 10^{-5}-1.0 \times 10^{-2}$ & \\
\hline $\mathrm{MnO}_{4}^{-}-\mathrm{Ru}(\mathrm{bpy})_{3}^{2+}-\mathrm{CL}$ method & $1.0 \times 10^{-4}$ & $1.0 \times 10^{-4}-0.5$ & 20 \\
\hline Ion chromatography-fluorescence & $2.0 \times 10^{-4}$ & $2.0 \times 10^{-4}-2.5 \times 10^{-5}$ & 21 \\
\hline Capillary electophoresis-UV & $2.0 \times 10^{-3}$ & $1.0 \times 10^{-2}-0.8$ & 22 \\
\hline Potentiometry & $2.0 \times 10^{-3}$ & $2.0 \times 10^{-3}-0.5$ & 23 \\
\hline Spectrophotometry & $1.0 \times 10^{-2}$ & $1.5 \times 10^{-2}-0.31$ & 24 \\
\hline
\end{tabular}

Table 3 Results for the determination of sulfite in powder sugar

\begin{tabular}{cccc}
\hline Sugar solution content $/\left(10^{-6} \mathrm{~mol} \cdot \mathrm{L}^{-1}\right)$ & Added $/\left(10^{-6} \mathrm{~mol} \cdot \mathrm{L}^{-1}\right)$ & Found $/\left(10^{-6} \mathrm{~mol} \cdot \mathrm{L}^{-1}\right)$ & Recovery $\%$ \\
\hline & 1.0 & 0.99 & 99 \\
3.51 & 2.0 & 1.92 & 96 \\
& 3.0 & 2.96 & 98.7 \\
2.15 & 1.0 & 0.92 & 92 \\
& 2.0 & 1.80 & 90 \\
\hline
\end{tabular}

\section{References}

1 Lin, J.-M.; Yamada, M. Trends Anal. Chem. 2003, 22, 99.

2 Lu, C.; Qu, F.; Lin, J.-M.; Yamada, M. Anal. Chim. Acta 2002, 47, 107.

3 Lu, C.; Lin, J.-M.; Huie, C. W. Talanta 2004, 63, 333.
4 Yamada, M.; Suzuki, S. Anal. Lett. 1984, 17, 251.

5 Kato, M.; Yamada, M.; Suzuki, S. Anal. Chem. 1984, 56, 2529.

6 Lin, J.-M.; Hobo, T. Anal. Chim. Acta 1996, 323, 69.

7 Huang, Y. L.; Kim, J. M.; Schmid, R. D. Anal. Chim. Acta 1992, 266, 317 . 
8 Meixner, F.; Jaeschke, W. Fresenius' Z. Anal. Chem. 1984, $317,343$.

9 Takeuchi, K.; Ibusuki, T. Anal. Chim. Acta 1985, 174, 359.

10 Syropoulos, A. B. E.; Sarantonis, G.; Calokerinos, A. C. Anal. Chim. Acta 1990, 239, 195.

11 Esteves da Silva, J. C. G.; Dias, J. R. M.; Magalhaes, J. M. C. S. Anal. Chim. Acta 2001, 450, 175.

12 Huang, Y. M.; Zhang, C.; Zhang, X. R.; Zhang, Z. J. Anal. Lett. 1999, 32, 1121.

13 Huang, Y. M.; Zhang, C.; Zhang, X. R.; Zhang, Z. J. Anal. Chim. Acta 1999, 391, 95.

14 Bonilha, J. B. S.; Chlericato, G.; Martins-Francheittl, S. M.; Ribaldo, E. J.; Quina, F. H. J. Phys. Chem. 1982, 86, 4941.

15 Zhang, G. F.; Chen, H. Y. Anal. Chim. Acta 2000, 409, 75.

16 Stauff, J.; Jaeschke, W. A. Z. Naturforschung B 1978, 33B, 293.
17 Meixner, F. X.; Jaeschke, W. A. Int. J. Environ. Anal. Chem. 1981, 10, 51 .

18 Paleos, C. M.; Vassiloppulos, G.; Nikokavouras, J. J. Photochem. 1982, 18, 327.

19 Ji, G. Z.; Zhang, G. M.; Tang, L.; Jiang, X. K. Acta Chim. Sinica 2003, 61, 970 (in Chinese).

20 Lin, J.-M.; Qu, F.; Yamada, M. Anal. Bioanal. Chem. 2002, 374, 1159.

21 Miura, Y.; Hatakeyama, M.; Hosino, T.; Haddad, P. R. J. Chromatogr. A 2002, 956, 77.

22 Jankovskiene, G.; Daunoravicius, Z.; Padarauskas, A. J. Chromatogr. A 2001, 934, 67.

23 Ekkad, N.; Huber, C. O. Anal. Chim. Acta 1996, 332, 155.

24 Decnop-Weever, L. G.; Kraak, J. C. Anal. Chim. Acta 1997, $337,125$.

(E0504212 LI, L. T.; ZHENG, G. C.) 